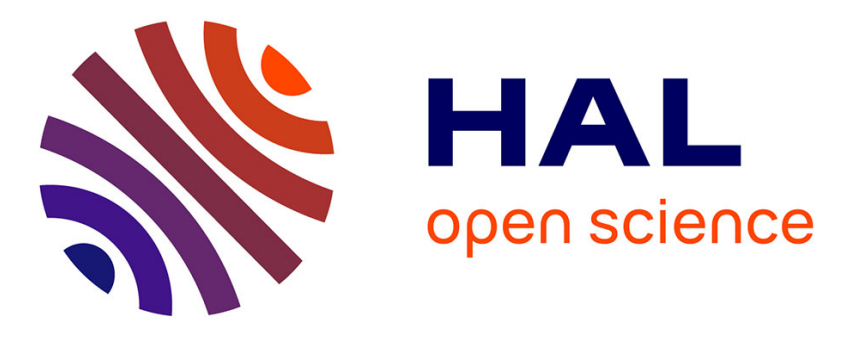

\title{
Surface Plasmon Resonances and Local Field Enhancement in Aluminum Nanoparticles Embedded in Silicon Nitride
}

Alexandre Fafin, Sophie Camelio, Frédéric Pailloux, David Babonneau

\section{- To cite this version:}

Alexandre Fafin, Sophie Camelio, Frédéric Pailloux, David Babonneau. Surface Plasmon Resonances and Local Field Enhancement in Aluminum Nanoparticles Embedded in Silicon Nitride. Journal of Physical Chemistry C, 2019, 123 (22), pp.13908-13917. 10.1021/acs.jpcc.9b03050 . hal-02151700

\author{
HAL Id: hal-02151700 \\ https://hal.science/hal-02151700
}

Submitted on 9 Jun 2019

HAL is a multi-disciplinary open access archive for the deposit and dissemination of scientific research documents, whether they are published or not. The documents may come from teaching and research institutions in France or abroad, or from public or private research centers.
L'archive ouverte pluridisciplinaire HAL, est destinée au dépôt et à la diffusion de documents scientifiques de niveau recherche, publiés ou non, émanant des établissements d'enseignement et de recherche français ou étrangers, des laboratoires publics ou privés. 


\section{Surface Plasmon Resonances and Local Field}

\section{Enhancement in Aluminum Nanoparticles Embedded in Silicon Nitride}

Alexandre Fafin, Sophie Camelio, ${ }^{*}$ Frédéric Pailloux, and David Babonneau

Institut Pprime, Département Physique et Mécanique des Matériaux, UPR 3346 CNRS, Université de Poitiers, SP2MI, TSA 41123, 86073 Poitiers Cedex 9, France.

E-mail: sophie.camelio@univ-poitiers.fr

Phone: +33 (0)5 49496751. Fax: +33 (0)5 49496692

${ }^{*}$ To whom correspondence should be addressed 


\begin{abstract}
We investigate the plasmonic response of periodic chains of flat aluminum nanoparticles capped with a transparent protective silicon nitride layer. The elaboration method is based on the nucleation and growth of nanoparticles by physical vapor deposition of $\mathrm{Al}$ at glancing incidence on a pre-patterned silicon nitride surface. A detailed structural characterization by transmission electron microscopy evidences a core@shell Al@AlN structure, with an in-plane particle size below $15 \mathrm{~nm}$ and a chain periodicity of about $30 \mathrm{~nm}$. The nanoparticle assembly exhibits surface plasmon resonances whose spectral positions depend on the polarization of the electric field with respect to the particle chains, as revealed by absorbance measurements. Near-field calculations highlight the possible overlap between the surface plasmon resonance and the interband transitions of aluminum. The plasmonic behavior of such nanoparticle arrays suggests a potential for polarization-selective near-field enhancement over a broad spectral range.
\end{abstract}

\title{
Introduction
}

Localized surface plasmons are collective oscillations of conduction electrons in metallic nanoparticles that can be resonantly excited by an external electromagnetic field (EMF). They manifest themselves as a subwavelength confinement of light, which is responsible for a strong optical absorption and scattering (far field) whereas the EMF intensity is greatly enhanced in the immediate vicinity of the nanoparticles (near field). The wavelength and intensity of the surface plasmon resonance (SPR), which typically falls into the visible region of the electromagnetic spectrum for noble metal nanoparticles (e.g., gold and silver), are extremely sensitive to the size, shape, organization, composition, and dielectric environment of the nanoparticles. ${ }^{1-3}$ The ability to suitably engineer plasmonic nanostructures has led to a large number of promising applications including, inter alia, thin-film solarcell technologies, ${ }^{4}$ nanoscale optical devices and integrated photonics, ${ }^{5,6}$ bio- or chemical sensors, ${ }^{7,8}$ heat nanosources,${ }^{9}$ surface-enhanced fluorescence, ${ }^{10,11}$ and surface-enhanced Ra- 
man spectroscopy. ${ }^{12-14}$ For designing such materials with an optimized optical response, it is therefore of paramount importance to address the influence of different critical parameters. ${ }^{15}$

For many years the most significant studies of localized surface plasmons were focused on gold and silver nanoparticles because of the favorable bulk dielectric properties of these metals in the visible and near infrared (NIR) spectral range. ${ }^{1}$ However, gold and silver suffer from inherent limitations such as high cost and low abundance in Earth, as well as increased losses arising in part from interband transitions (IT) at wavelengths shorter than $550 \mathrm{~nm}(2.25 \mathrm{eV})$ and $350 \mathrm{~nm}(3.54 \mathrm{eV})$, respectively. Free-standing silver nanoparticles are, furthermore, plagued by rapid oxidation and sulfurization issues that degrade their plasmonic properties over time. Hence, alternative plasmonic materials have lately received ever-growing attention. ${ }^{16,17}$ Amongst the most commonly suggested materials, aluminum plasmonic nanoparticles are currently at the focus of numerous studies. ${ }^{18}$ Apart from its cheapness and natural abundance, the advantages of aluminum are substantial both from fundamental and applied points of view: aluminum is characterized by a great amenability to manufacturing processes and compatibility with semiconductor and nanoelectronics technologies; moreover, owing both to its high-energy plasma frequency and the absence of IT in the visible and ultraviolet (UV) ranges, aluminum nanoparticles exhibit SPR that can be tuned over a broad spectral range from the NIR down to the deep UV (below $200 \mathrm{~nm}$ ) with a strong size and shape dependence of the SPR wavelength. ${ }^{19-36}$ Compared to noble metals, these properties makes aluminum an appealing and practical material for UV-plasmonics applications ${ }^{19,20,29,32-35}$ such as, for example, broadband light trapping in thin-film photovoltaic devices. ${ }^{27,36-40}$ It is also worth noting that, despite - or thanks to - its IT around $800 \mathrm{~nm}(1.55 \mathrm{eV})$ and high losses in the NIR, aluminum nanoparticles are suggested as a promising alternative for light absorption and near-field enhancement in this spectral region, as well as for designing efficient integrated thermoplasmonic devices. ${ }^{17,21,26,41}$

Several approaches have been reported to fabricate aluminum plasmonic nanostructures like lithographic methods, ${ }^{19-31}$ physical vapor deposition, ${ }^{33-36,39,40,42-44}$ cluster beam depo- 
sition, ${ }^{45}$ laser ablation in liquids, ${ }^{46}$ and wet-chemical synthesis. ${ }^{37,47}$ However, still to this day, technical challenges make it difficult to achieve the production of ultrafine aluminum nanoparticles $(<20 \mathrm{~nm})$ with controlled morphology and composition. ${ }^{48}$ This is primarily because aluminum easily oxidizes when exposed to air, which can, at best, lead to the formation of a passivating oxide layer that causes a red-shift of the SPR, ${ }^{19,22-24,29}$ and, at worst, dramatically alter the internal particle structure with deleterious consequences for the resulting electronic and plasmonic properties. ${ }^{49,50}$

In this article, we report on the far-field and near-field optical properties of aluminum (Al) plasmonic nanoparticles embedded in silicon nitride $\left(\mathrm{Si}_{3} \mathrm{~N}_{4}\right)$ thin films. Al nanoparticle arrays with dimensions and gaps below the resolution of lithographic techniques were produced by glancing-angle ion-beam deposition on nanoripple patterns prepared by ion-beam sputtering (IBS) of amorphous $\mathrm{Si}_{3} \mathrm{~N}_{4}$ surfaces at oblique incidence. ${ }^{34,35,51-56}$ After metal deposition and prior to exposure to the atmosphere, the nanoparticle arrays were covered with a $20 \mathrm{~nm}$ thick $\mathrm{Si}_{3} \mathrm{~N}_{4}$ capping-layer, thus ensuring optimal protection for the nanoparticles against oxidation. $\mathrm{Si}_{3} \mathrm{~N}_{4}$-embedded $\mathrm{Al}$ nanoparticles were characterized by transmission electron microscopy (TEM) using direct spatial imaging, diffraction, and spectroscopy. Far-field optical properties were investigated by visible-NIR polarized-light transmission spectroscopy, while finite-difference time-domain (FDTD) calculations were performed to simulate the near-field behavior.

\section{Experimental details}

\section{Sample preparation}

Self-organized $\mathrm{Al}$ nanoparticles embedded in $\mathrm{Si}_{3} \mathrm{~N}_{4}$ thin films were fabricated in a dual IBS Nordiko $^{T M}$ chamber following a four-step sequence under high vacuum $\left(\sim 6 \times 10^{-8}\right.$ mbar base pressure), as described in Ref. 52-56. Amorphous $\mathrm{Si}_{3} \mathrm{~N}_{4}$ layers totaling up to $280 \mathrm{~nm}$ in thickness were first grown at $200^{\circ} \mathrm{C}$ onto surface-oxidized Si, fused silica substrates and 
$\mathrm{NaCl}$ single crystals. $\mathrm{Si}_{3} \mathrm{~N}_{4}$ deposition was accomplished at normal incidence and at a rate of $0.047 \mathrm{~nm} \cdot \mathrm{s}^{-1}$, by IBS of a $\mathrm{Si}_{3} \mathrm{~N}_{4}$ target while carrying out ion assistance by a $50 \mathrm{eV}$ nitrogen ion-beam oriented at $45^{\circ}$ with respect to the substrate surface-normal. The as-grown films were smooth (root-mean-square roughness $\sigma_{\mathrm{rms}} \approx 0.3 \mathrm{~nm}$ ) and were transparent in the visible-NIR region with a refractive index typically of 2.05 at $600 \mathrm{~nm}(2.07 \mathrm{eV})$. Ion erosion of $\mathrm{Si}_{3} \mathrm{~N}_{4}$ surfaces was then carried out at room temperature or at $200{ }^{\circ} \mathrm{C}$ with a collimated $1 \mathrm{keV} \mathrm{Xe}^{+}$-ion beam produced from a filamentless radio-frequency ion source at a sputtering angle of $55^{\circ}$ with respect to the surface normal and a total fluence of about $1.25 \times 10^{18}$ ions $\mathrm{cm}^{-2}$. This led to the formation of periodic patterns consisting of unidirectional ripples oriented in the direction perpendicular to the projection of the ion beam. ${ }^{52,57}$ An example of periodic nanoripple patterns formed by IBS under off-normal incidence of amorphous $\mathrm{Si}_{3} \mathrm{~N}_{4}$ layers is presented in Fig. 1. The surface topography obtained by atomic force microscopy (AFM) exhibits shallow ripples with a periodicity of about $30 \mathrm{~nm}$ and a height ranging from $\sim 2$ to $4 \mathrm{~nm}$ depending on the temperature.
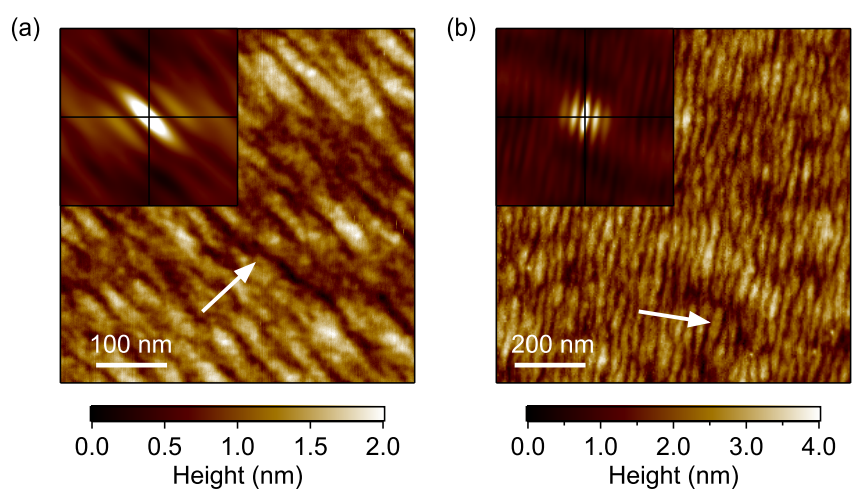

Figure 1: AFM topographic images of amorphous $\mathrm{Si}_{3} \mathrm{~N}_{4}$ thin films deposited onto surfaceoxidized Si after $1 \mathrm{keV} \mathrm{Xe}^{+}$-ion exposure (a) at $200^{\circ} \mathrm{C}$ and (b) at room temperature. Corresponding autocorrelation functions of the images are shown in inset. The projection of the ion-beam direction onto the surface is indicated by the white arrows.

The pre-patterned $\mathrm{Si}_{3} \mathrm{~N}_{4}$ surfaces were finally used as templates for the self-organized growth of $\mathrm{Al}$ nanoparticles followed by the deposition of a $20 \mathrm{~nm}$-thick $\mathrm{Si}_{3} \mathrm{~N}_{4}$ capping-layer. $\mathrm{Al}$ was deposited by IBS at a rate of $0.029 \mathrm{~nm} \cdot \mathrm{s}^{-1}$ under a glancing incidence of $6^{\circ}$ from the 
mean surface, while the metal flux was oriented perpendicular to the ripples, thus ensuring replication of the lateral order between ripples by shadowing effects. The temperature was kept constant throughout the ion erosion and $\mathrm{Al}$ deposition steps, which were immediately followed by a thermal annealing at $200^{\circ} \mathrm{C}$ for $30 \mathrm{~min}$ and by the subsequent deposition of the protective $\mathrm{Si}_{3} \mathrm{~N}_{4}$ layer at $200{ }^{\circ} \mathrm{C}$ to prevent contamination and possible evolution of the nanoparticle arrays through exposure to ambient conditions.

\section{Characterization methods}

The structure, morphology and spatial distribution of the nanoparticles were analyzed by TEM with a JEOL 2200FS microscope fitted with an in-column $\Omega$-filter and a Schottky field emission gun operated at $200 \mathrm{kV}$ providing an energy resolution close to $0.8 \mathrm{eV}$. Prior to the observation, free-standing films deposited on $\mathrm{NaCl}$ single crystals were transferred onto copper or molybdenum grids after dissolving the substrate in purified water. Direct imaging was carried out from plane views by scanning TEM (STEM) in annular dark-field (ADF) and high-angle ADF (HAADF) modes; the former being sensitive to diffraction contrasts, the latter to the local mass and thickness of the sample. The image sampling was typically set to $0.52 \mathrm{~nm}$ per pixel $(\mathrm{px})$ with a probe size of $0.7 \mathrm{~nm}$ in order to optimize the signal-tonoise ratio while keeping the spatial resolution required to image nanoparticles. ADF and HAADF signals were acquired simultaneously by using a Gatan Digiscan II system.

The total thickness of the $\mathrm{Si}_{3} \mathrm{~N}_{4} / \mathrm{Al} / \mathrm{Si}_{3} \mathrm{~N}_{4}$ plane views ranging between $\sim 40 \pm 5 \mathrm{~nm}$ leads to a strong inelastic scattering of electrons by the sample, detrimental for the detection of phases present in low amount. In order to weaken this inherent inelastic background from the diffraction patterns, and detect the signal of nano-crystallites, energy filtered selected area electron diffraction (EF-SAED) was employed with an energy selection slit around the zero-loss peak ranging between $5 \mathrm{eV}$ and $7 \mathrm{eV}$. Finally, image series (data cubes) were recorded in the energy filtered TEM (EF-TEM) mode. Data cubes were acquired in the low-losses range (from -5 to $35 \mathrm{eV}$ ) with an energy selection slit of $0.5 \mathrm{eV}$ (resp. $1 \mathrm{eV}$ ) and 
an energy sampling of $0.2 \mathrm{eV}$ (resp. $0.5 \mathrm{eV}$ ). Images were recorded with a Gatan Ultra-Scan CCD camera $\left(2048 \times 2048 \mathrm{px}^{2}\right)$ using a binning of $4 \times 4$ to improve the signal-to-noise ratio, leading to a spatial sampling of $0.47 \mathrm{~nm}$ per px consistent with the size of the nanoparticles to be analyzed. Such data cubes often suffers from many artefacts such as non-isochromaticity coming from the aberration of the $\Omega$-filter and/or spatial drift resulting from the lack of stability of the sample over the several tens of minutes required to record a single datacube. Thus, when necessary, non-isochromaticity and spatial drift were corrected using the procedure described in Ref. 58. The energy drift was estimated to be less than $2 \mathrm{eV} /$ hour (i.e., the plasmons of $\mathrm{Al}$ and $\mathrm{Si}_{3} \mathrm{~N}_{4}$ arise at the right energy-loss positions with respect to the zero-loss peak). Multiple scattering was then deconvolved by the Fourier-Log method as implemented in Digital Micrograph. ${ }^{59}$ Finally, in order to lower the influence of long range intensity modulations of the background (thickness variations of the $\mathrm{Si}_{3} \mathrm{~N}_{4}$ matrix) and to enhance the contrast of the nanoparticles, a high-pass filter was applied along the energy-loss axis prior to image segmentation.

The far-field optical response of the samples deposited on fused silica substrates was investigated by means of spectroscopic transmission using a Cary 5000 spectrophotometer from Agilent Technologies equipped with a rotating polarizer. Transmittance measurements were performed at normal incidence (beam diameter $\sim 3 \mathrm{~mm}$ ) in the spectral range between $250 \mathrm{~nm}(4.96 \mathrm{eV})$ and $2200 \mathrm{~nm}(0.56 \mathrm{eV})$ with a $1 \mathrm{~nm}$-step using longitudinal $(\|)$ or transverse $(\perp)$ polarization with respect to the ripple direction. In addition to far-field measurements, numerical simulations were performed by FDTD calculations using the FDTD Solutions software purchased from Lumerical. ${ }^{60}$ 
(a)

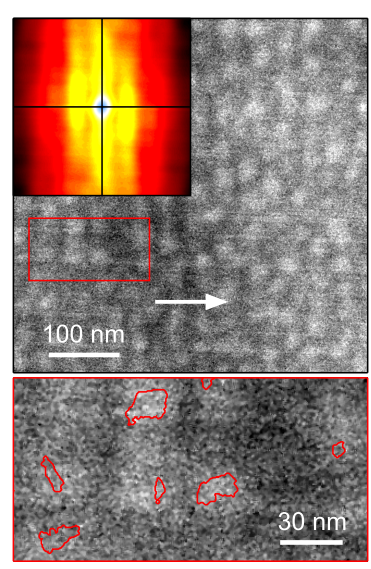

(b)

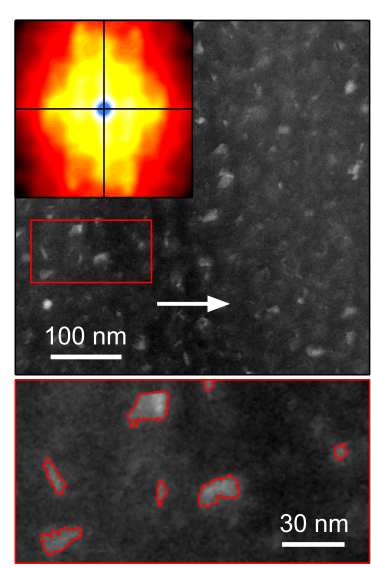

Figure 2: (a) HAADF-STEM and (b) ADF-STEM images of $\mathrm{Si}_{3} \mathrm{~N}_{4}$-capped Al nanoparticles grown at $200{ }^{\circ} \mathrm{C}$ on a rippled $\mathrm{Si}_{3} \mathrm{~N}_{4}$ thin film $\left(t_{\mathrm{Al}}=4.4 \mathrm{~nm}\right)$. Corresponding ACFs of the images are shown in inset and the projection of the $\mathrm{Al}$ flux direction onto the surface is indicated by the white arrows. Zoomed areas indicated by the red rectangles are also exhibited (superimposed contour lines are the boundaries of the bright spots obtained from digital processing of the ADF-STEM image).

\section{Results and discussion}

\section{Al deposition at $200^{\circ} \mathrm{C}$}

Fig. 2 shows plane-view HAADF-STEM and ADF-STEM images of a $\mathrm{Si}_{3} \mathrm{~N}_{4} / \mathrm{Al} / \mathrm{Si}_{3} \mathrm{~N}_{4}$ trilayer resulting from the deposition of an effective $\mathrm{Al}$ thickness of $t_{\mathrm{Al}}=4.4 \mathrm{~nm}$ at $200{ }^{\circ} \mathrm{C}$. Despite low contrast, arising both from the low $Z$-value of $\mathrm{Al}(Z=13)$ and from the thinness of the Al deposit, the HAADF-STEM image displayed in Fig. 2(a) clearly reveals the presence of individual nanoparticles of irregular shape. However, it is worth noting that the nanoparticles are predominantly elongated and aligned in the direction perpendicular to the $\mathrm{Al}$ flux direction (i.e., along the underlying ripples). This is highlighted by the existence of periodic lines in the corresponding autocorrelation function (ACF), which gives a visual impression of the degree of ordering within the nanoparticle array. ${ }^{61}$ Furthermore, the ACF analysis of the HAADF-STEM image yields a mean distance between nanoparticles in the transverse direction of $\Lambda^{\perp}=35.5 \mathrm{~nm}$, approaching the periodicity of the pre-patterned $\mathrm{Si}_{3} \mathrm{~N}_{4}$ surface. These findings suggest that the nanoparticle growth proceeds by replication of the rippled 
surface pattern as a result of shadowing effects together with low mobility and high adhesion coefficient of aluminum. Moreover, as seen in Fig. 2(b), the ADF-STEM image taken from the same zone of the trilayer shows a number of bright areas corresponding to the presence of nano-crystallites smaller in size than the nanoparticles observed in the HAADF mode (see zoomed images). This observation suggests that the nanoparticles are made of several $\mathrm{Al}$ crystallites and/or composed of different phases.
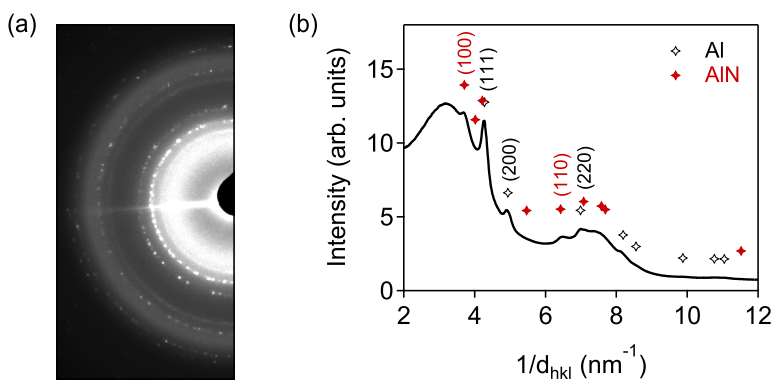

Figure 3: (a) EF-SAED pattern of $\mathrm{Si}_{3} \mathrm{~N}_{4}$-capped $\mathrm{Al}$ nanoparticles grown at $200^{\circ} \mathrm{C}$ on a rippled $\mathrm{Si}_{3} \mathrm{~N}_{4}$ thin film $\left(t_{\mathrm{Al}}=4.4 \mathrm{~nm}\right)$. (b) Corresponding electron diffraction averaged profile together with the position of the main lines for $f c c-\mathrm{Al}$ and $w$-AlN. ${ }^{62}$

EF-SAED was used to identify the phases formed during deposition of the $\mathrm{Si}_{3} \mathrm{~N}_{4} / \mathrm{Al} / \mathrm{Si}_{3} \mathrm{~N}_{4}$ trilayer grown at $200^{\circ} \mathrm{C}$. As a typical example, the EF-SAED pattern displayed in Fig. 3 is the superposition of two sets of reflections that can be indexed as those of face centeredcubic $\mathrm{Al}\left(f c c-\mathrm{Al}, \mathrm{Fm} \overline{3} \mathrm{~m}\right.$ space group) and wurtzite $\mathrm{AlN}$ ( $w$-AlN, $P 6_{3} \mathrm{mc}$ space group) nanocrystallites with random orientation. More specifically, it can be observed that AlN exhibits diffraction peaks corresponding to the (100) and (110) crystal planes of $w$-AlN. However, although the presence of $f c c-\mathrm{Al}$ and $w$-AlN nano-crystallites can be clearly identified, they cannot be spatially located from HAADF-STEM and ADF-STEM images.

Fig. 4(a)-4(c) present typical EF-TEM images acquired at different energy losses, which roughly correspond to the bulk plasmon energies of $\mathrm{Al}(\sim 15 \mathrm{eV})$, AlN $(\sim[20-21] \mathrm{eV}$ depending on the strain state $\left.{ }^{63}\right)$, and $\mathrm{Si}_{3} \mathrm{~N}_{4}\left(\sim 23.7 \mathrm{eV}^{64}\right)$, respectively (for more details refer to the Supporting Information, section I). The Al map acquired at $15.2 \pm 0.7 \mathrm{eV}$ [Fig. 4(a)] shows periodic chains of elongated nanoparticles ( $11.3 \mathrm{~nm}$ in size), which 
(a)

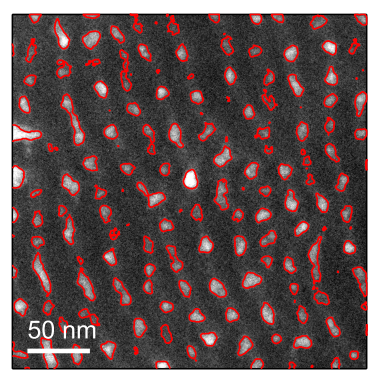

(c)

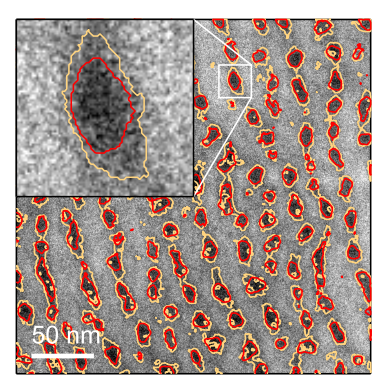

(b)

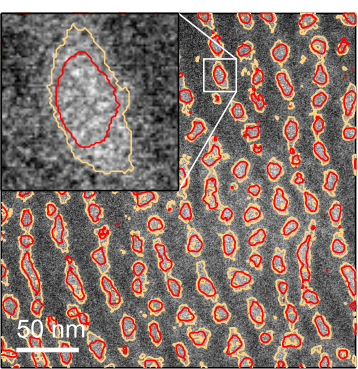

(d)

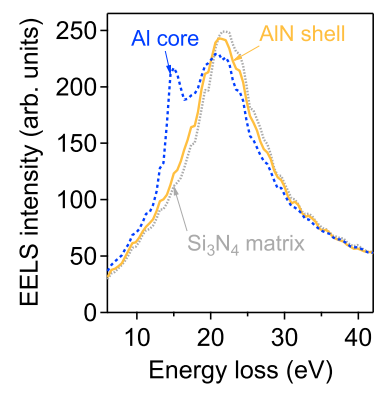

Figure 4: EF-TEM images acquired at (a) $[14.5-15.9] \mathrm{eV}$, (b) $[18.3-19.7] \mathrm{eV}$, and (c) [23.424.8] eV energy losses on $\mathrm{Si}_{3} \mathrm{~N}_{4}$-capped $\mathrm{Al}$ nanoparticles grown at $200{ }^{\circ} \mathrm{C}$ on a rippled $\mathrm{Si}_{3} \mathrm{~N}_{4}$ thin film $\left(t_{\mathrm{Al}}=4.4 \mathrm{~nm}\right)$. The superimposed contour lines are the boundaries of the particles obtained by digital image processing. (d) Electron energy-loss spectra corresponding to different probe positions.

are preferentially oriented in the direction parallel to the ripples. EF-TEM images were carefully analyzed by digital image processing ${ }^{54}$ assuming ellipsoidal nanoparticles with inplane diameters $D_{\text {core }}^{\|}$and $D_{\text {core }}^{\perp}$ in the longitunidal and transverse directions, respectively (Table 1). As a result of shadowing effects and inhomogeneous anisotropic coalescence in the zones illuminated by the metal flux during deposition, ${ }^{56}$ the Al nanoparticles show an average in-plane aspect ratio $D_{\text {core }}^{\|} / D_{\text {core }}^{\perp} \approx 1.4$ (in line with the elongated shapes observed in HAADF-STEM images) with a broader size distribution in the longitudinal direction, as reflected in the standard deviation ratio $\left(\sigma_{D_{\text {core }}^{\|}} / \sigma_{D_{\text {core }}^{\perp}} \approx 3.5\right)$. Clearly, the AlN map acquired at $19.0 \pm 0.7 \mathrm{eV}$ [Fig. 4(b)] provides evidence of the formation of a homogeneous nitride shell around the $\mathrm{Al}$ cores, with an average thickness of $t_{\text {shell }}^{\|}=3.5 \mathrm{~nm}$ in the longitudinal direction and only $t_{\text {shell }}^{\perp}=0.8 \mathrm{~nm}$ in the transverse direction. It is worth noting that experimental results showing that an interfacial AlN thin layer is formed during deposition of $\mathrm{Al}$ on $\mathrm{Si}_{3} \mathrm{~N}_{4}$ have already been reported, which in turn prevents $\mathrm{Al}$ to diffuse into $\mathrm{Si}_{3} \mathrm{~N}_{4} \cdot{ }^{65}$ However, in 
our case, anisotropic growth of the AlN shell is achieved with $t_{\text {shell }}^{\|}>t_{\text {shell }}^{\perp}$, probably due to the presence of small $\mathrm{Al}$ nanoparticles into the chains which are completely nitrided and have coalesced with larger nanoparticles. The existence of anisotropic Al@AlN core@shell nanoparticles is also consistent with the $\mathrm{Si}_{3} \mathrm{~N}_{4}$ map acquired at $24.1 \pm 0.7 \mathrm{eV}$ [Fig. 4(c)], which exhibits bright areas located between the Al@AlN-rich regions. Moreover, electron energy-loss spectra corresponding to different probe positions display various features and characteristics [Fig. 4(d)]. Indeed, a low-loss peak centered at $\sim 15 \mathrm{eV}$ (Al bulk plasmon) together with a broader peak centered beyond $20 \mathrm{eV}$ (due to the contribution of both AlN and $\mathrm{Si}_{3} \mathrm{~N}_{4}$ bulk plasmons) were measured on the nanoparticle cores [blue spectrum in Fig. 4(d)]. In contrast, a single broad peak was detected in regions outside of the cores [orange and gray spectra in Fig. 4(d)], with the plasmon energy shifting to lower (resp. higher) values in AlN-rich (resp. $\mathrm{Si}_{3} \mathrm{~N}_{4}$-rich) regions in accordance with the $\mathrm{AlN}$ and $\mathrm{Si}_{3} \mathrm{~N}_{4}$ bulk plasmon energies. ${ }^{63,64}$

Table 1: Morphological parameters retrieved from the careful analysis of EFTEM images acquired on $\mathrm{Si}_{3} \mathrm{~N}_{4}$-capped Al nanoparticles grown on rippled $\mathrm{Si}_{3} \mathrm{~N}_{4}$ thin films: effective Al thickness $\left(t_{\mathrm{Al}}\right)$, temperature during Al deposition $\left(T_{\mathrm{d}}\right)$, annealing temperature $\left(T_{\mathrm{a}}\right)$, interparticle distance in the longitudinal $\left(\Lambda^{\|}\right)$and transverse $\left(\Lambda^{\perp}\right)$ directions, average in-plane diameter of the Al nanoparticle core in the longitudinal ( $\left.D_{\text {core }}^{\|}\right)$and transverse $\left(D_{\text {core }}^{\perp}\right)$ directions, average thickness of the AlN shell in the longitudinal $\left(t_{\text {shell }}^{\|}\right)$and transverse $\left(t_{\text {shell }}^{\perp}\right)$ directions. The numbers in brackets refer to the corresponding standard deviations.

\begin{tabular}{ccccccccc}
\hline $\begin{array}{c}t_{\mathrm{Al}} \\
(\mathrm{nm})\end{array}$ & $\begin{array}{c}T_{\mathrm{d}} \\
\left({ }^{\circ} \mathrm{C}\right)\end{array}$ & $\begin{array}{c}T_{\mathrm{a}} \\
\left({ }^{\circ} \mathrm{C}\right)\end{array}$ & $\begin{array}{c}\Lambda^{\|} \\
(\mathrm{nm})\end{array}$ & $\begin{array}{c}\Lambda^{\perp} \\
(\mathrm{nm})\end{array}$ & $\begin{array}{c}D_{\text {core }} \\
(\mathrm{nm})\end{array}$ & $\begin{array}{c}D_{\text {core }}^{\perp} \\
(\mathrm{nm})\end{array}$ & $\begin{array}{c}t_{\text {shell }}^{\|} \\
(\mathrm{nm})\end{array}$ & $\begin{array}{c}t_{\text {shell }}^{\perp} \\
(\mathrm{nm})\end{array}$ \\
\hline 4.4 & 200 & - & $26.4(1.7)$ & $26.4(0.3)$ & $13.9(6.9)$ & $10.1(1.9)$ & $3.5(1.7)$ & $0.8(0.6)$ \\
2.9 & 25 & - & $27.2(2.2)$ & $26.2(0.3)$ & $14.4(6.8)$ & $9.6(3.3)$ & $1.3(0.9)$ & $0.5(0.4)$ \\
2.9 & 25 & 300 & $29.1(5.2)$ & $29.8(0.9)$ & $13.5(8.1)$ & $9.6(3.8)$ & $0.7(0.9)$ & $0.4(0.4)$ \\
2.9 & 25 & 400 & $27.7(1.8)$ & $31.0(0.7)$ & $14.5(7.9)$ & $9.1(3.2)$ & $1.8(1.2)$ & $0.9(0.5)$ \\
\hline
\end{tabular}




\section{Al deposition at room temperature}

\section{Structure and morphology}

A representative EF-SAED pattern together with its corresponding averaged profile obtained from $\mathrm{Si}_{3} \mathrm{~N}_{4}$-capped $\mathrm{Al}$ nanoparticles grown at room temperature on a rippled $\mathrm{Si}_{3} \mathrm{~N}_{4}$ thin film $\left(t_{\mathrm{Al}}=2.9 \mathrm{~nm}\right)$ are shown in Fig. 5(a)-5(b). In comparison with Fig. 3, it can be seen that the diffraction rings corresponding to $f c c-\mathrm{Al}$ are broader whereas those corresponding to $w$-AlN are indistinguishable from the background. These observations suggest that the lower the $\mathrm{Al}$ deposition temperature, the smaller are the coherently scattering domains. In other words, the $\mathrm{Al}$ deposition temperature strongly affects the size of the nano-crystallites and/or their degree of crystallinity, which may have an impact on the resulting optical properties. Accordingly, after $\mathrm{Al}$ deposition at room temperature, elemental analysis by EF-TEM still highlights the presence of irregularly-shaped Al@AlN core@shell nanoparticles with $D_{\text {core }}^{\|} / D_{\text {core }}^{\perp} \approx 1.5$ [Fig. $\left.5(\mathrm{c})-5(\mathrm{~d})\right]$, but with an average shell thickness reduced to

$t_{\text {shell }}^{\|}=1.3 \mathrm{~nm}$ and $t_{\text {shell }}^{\perp}=0.5 \mathrm{~nm}$ in the longitudinal and transverse directions, respectively (Table 1).

\section{Far-field and near-field optical properties}

In Fig. 6(a), the absorbance spectrum of $\mathrm{Si}_{3} \mathrm{~N}_{4}$-capped $\mathrm{Al}$ nanoparticles grown at room temperature on a rippled $\mathrm{Si}_{3} \mathrm{~N}_{4}$ thin film $\left(t_{\mathrm{Al}}=2.9 \mathrm{~nm}\right)$ exhibits a strongly dichroic behavior that originates from the anisotropic nanostructure of the sample. Indeed, the Al@AlN core@shell nanoparticles organized in linear chains give rise to different absorption bands depending on the polarization of the incident light with respect to the ripple direction. A strong absorption, readily ascribable to the transverse SPR excitation of the nanoparticles, is found at $462 \mathrm{~nm}(2.68 \mathrm{eV})$ for a polarization perpendicular to the ripple direction, while a broad absorption at about $581 \mathrm{~nm}(2.13 \mathrm{eV})$ with an additional weak absorption at $912 \mathrm{~nm}(1.36 \mathrm{eV})$ are present for a longitudinal polarization. It is worth noting that the optical properties of 
(a)

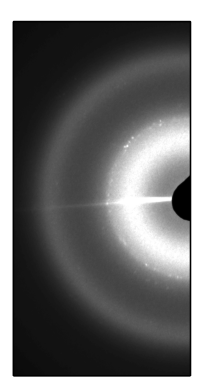

(c)

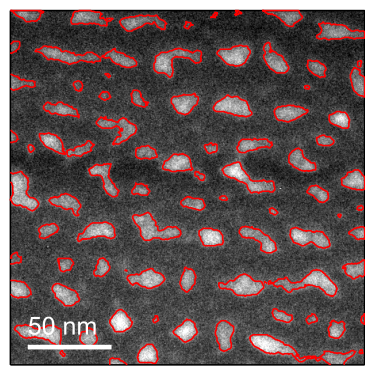

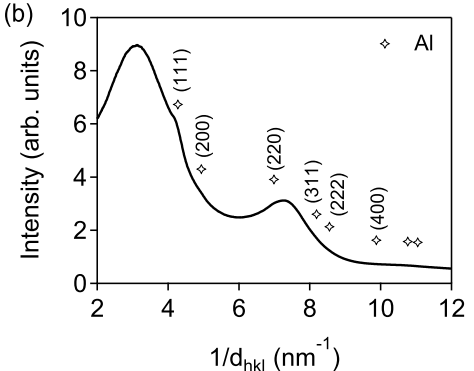

(d)

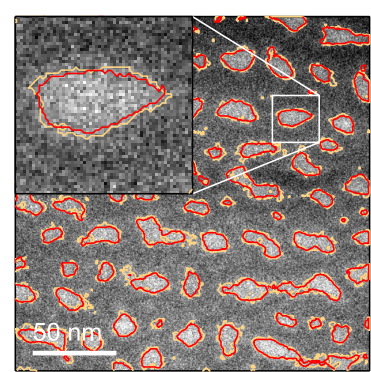

Figure 5: (a) EF-SAED pattern of $\mathrm{Si}_{3} \mathrm{~N}_{4}$-capped $\mathrm{Al}$ nanoparticles grown at room temperature on a rippled $\mathrm{Si}_{3} \mathrm{~N}_{4}$ thin film $\left(t_{\mathrm{Al}}=2.9 \mathrm{~nm}\right)$. (b) Corresponding electron diffraction averaged profile together with the position of the main lines for $f c c-\mathrm{Al} .{ }^{62} \mathrm{EF}-\mathrm{TEM}$ images acquired at (c) $[15-16] \mathrm{eV}$ and (d) $[17-18] \mathrm{eV}$ energy losses. The superimposed contour lines are the boundaries of the particles obtained by digital image processing.

the sample were stable after 4 months of exposure to atmospheric conditions (see Fig. S2, Supporting Information). In addition, similar plasmonic dichroism has been reported for Ag, $\mathrm{Au}$, and $\mathrm{Au}_{x} \mathrm{Ag}_{1-x}$ nanoparticles produced by glancing-angle ion-beam deposition on rippled alumina surfaces, as described in Ref. 52-55. In these papers, we found a red-shifted and broader longitudinal SPR as compared to the transverse one, partly because of a broad size distribution in the longitudinal direction but mainly because of near-field interactions inside the linear chains due to very small interparticle gaps $\left(g^{\|}=\Lambda^{\|}-D_{\text {core }}^{\|}<D_{\text {core }}^{\|} / 3\right)$. Nevertheless, in the present case, the average interparticle gap is not small enough $\left(g^{\|} \approx 0.9 D_{\text {core }}^{\|}\right)$to induce a strong coupling between the $\mathrm{Al}$ nanoparticles. The dichroism is therefore most likely associated with the anisotropic shape of the $\mathrm{Al}$ nanoparticles $\left(D_{\text {core }}^{\|} / D_{\text {core }}^{\perp} \approx 1.5\right)$ whereas inhomogeneous broadening of the longitudinal SPR may be primarily due to the broad size distribution $\left(\sigma_{D_{\text {core }}^{\|}} / D_{\text {core }}^{\|}=0.47\right)$ and irregular shape of the nanoparticles, which contributes to the appearance of multiple surface plasmon modes. ${ }^{66}$ Referring to the dielectric function 


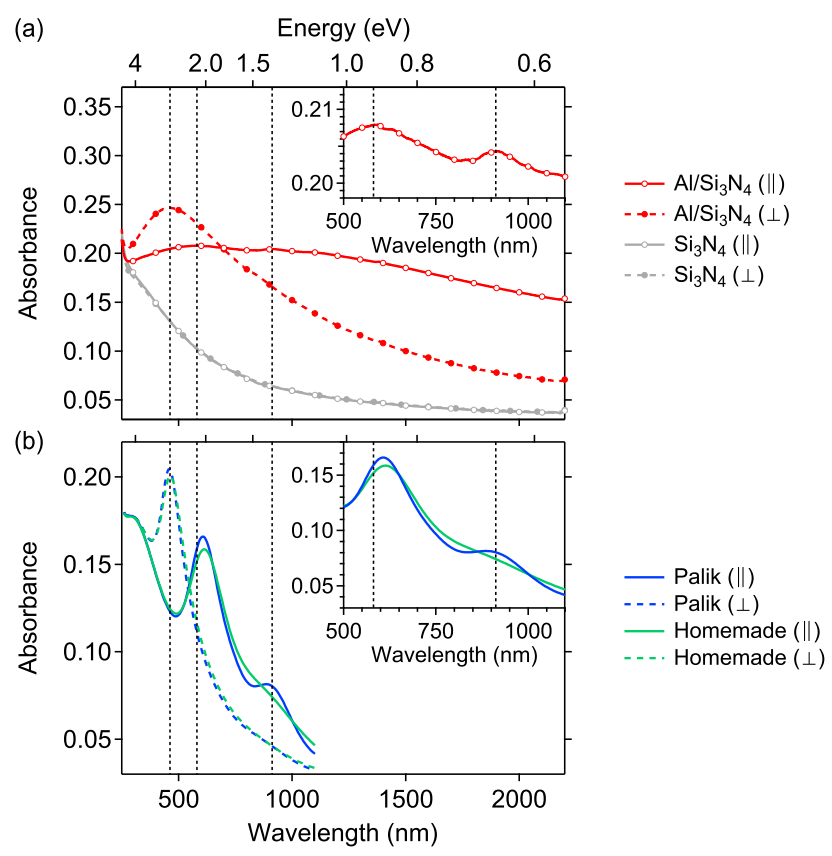

Figure 6: (a) Experimental absorption spectra with longitudinal and transverse polarizations of the incident light with respect to the ripple direction for $\mathrm{Si}_{3} \mathrm{~N}_{4}$-capped $\mathrm{Al}$ nanoparticles grown at room temperature on a rippled $\mathrm{Si}_{3} \mathrm{~N}_{4}$ thin film $\left(t_{\mathrm{Al}}=2.9 \mathrm{~nm}\right)$. Corresponding absorption spectra measured for a rippled $\mathrm{Si}_{3} \mathrm{~N}_{4}$ thin film capped with $\mathrm{Si}_{3} \mathrm{~N}_{4}$ are also presented for comparison. (b) Absorption spectra calculated by FDTD method using the morphological parameters gathered in Table 1 and the dielectric functions shown in Fig. 7. The vertical dotted lines represent the spectral positions of the experimental absorption maxima.

of $\mathrm{Al}$, as shown in Fig. 7(a), the additional weak absorption at $912 \mathrm{~nm}$ may result from the coupling between the longitudinal SPR and the IT of Al near $800 \mathrm{~nm}(1.55 \mathrm{eV}){ }^{21,22,67}$ Since the transverse SPR is shifted to lower wavelengths (higher energies) compared to the longitudinal mode, the overlap of the IT and the SPR should weaken, as is indeed observed in Fig. 6(a).

The spectral optical properties of Al@AlN core@shell nanoparticle chains embedded in $\mathrm{Si}_{3} \mathrm{~N}_{4}$ were calculated by FDTD method using the experimental dielectric functions determined from ellipsometric measurements of a $27 \mathrm{~nm}$-thick Al film and a $50 \mathrm{~nm}$-thick $\mathrm{Si}_{3} \mathrm{~N}_{4}$ film grown by ion-beam deposition at room temperature and at $200^{\circ} \mathrm{C}$, respectively [Fig. $7(\mathrm{a})$ ]. The dielectric function of the AlN outer shell was estimated from Ref. 69, assuming a refractive index equal to the average of the ordinary and extraordinary indices to take into 

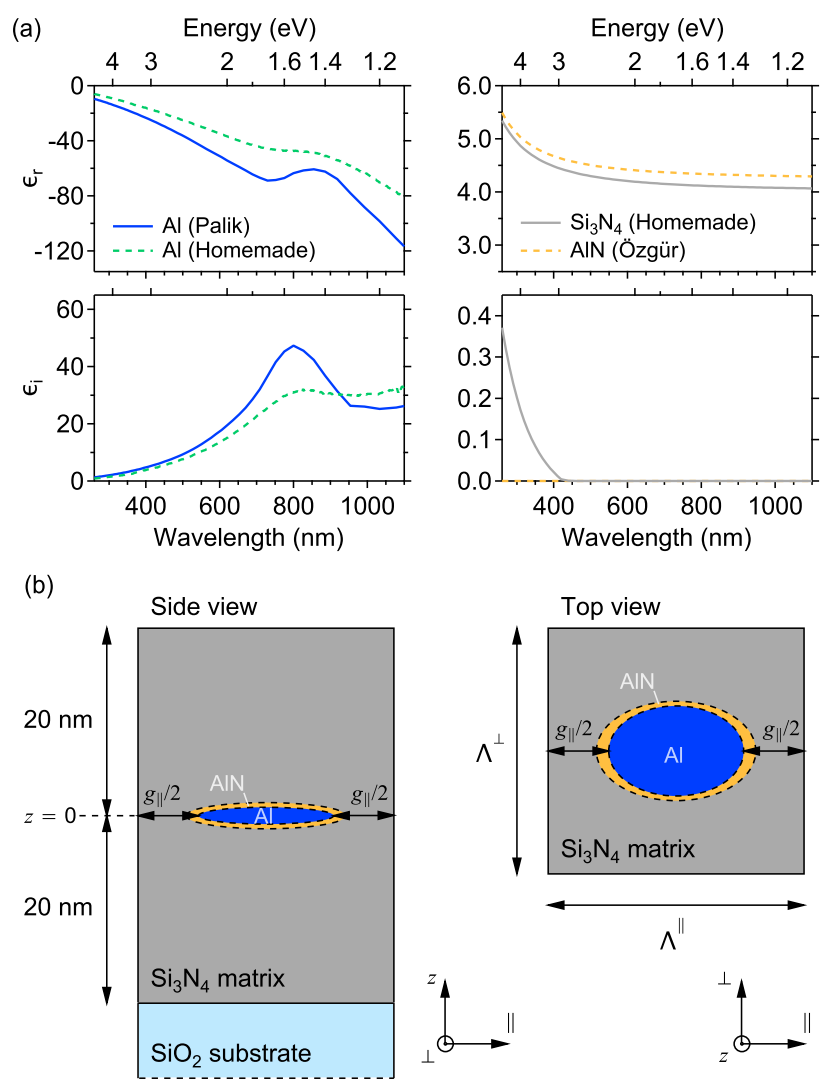

Figure 7: (a) Real part and imaginary part of the dielectric functions for $\mathrm{Al}, \mathrm{Si}_{3} \mathrm{~N}_{4}$, and AlN. The data for Al (Palik) and AlN (Özgür) were taken from Ref. 68 and 69, respectively. The data for $\mathrm{Al}$ (Homemade) and $\mathrm{Si}_{3} \mathrm{~N}_{4}$ (Homemade) were experimentally determined from spectroscopic ellipsometry measurements of thin films grown by ion-beam deposition at room temperature and at $200{ }^{\circ} \mathrm{C}$, respectively. (b) Sketch of the configuration used to perform FDTD calculations for Al@AlN core@shell nanoparticles surrounded by a $\mathrm{Si}_{3} \mathrm{~N}_{4}$ matrix deposited on a fused silica substrate.

account the birefringence of $w$-AlN. As shown in Fig. 7(b), we considered an assembly of identical ellipsoidal Al nanoparticles with in-plane dimensions corresponding to the average experimental sizes, $D_{\text {core }}^{\|}$and $D_{\text {core }}^{\perp}$, as determined by EF-TEM analysis (Table 1$)$. The values given in Table 1 were also used for fixing the AlN shell thickness $\left(t_{\text {shell }}^{\|}\right.$and $\left.t_{\text {shell }}^{\perp}\right)$, while the thickness of the shell in the $z$ direction was assumed to be equal to the one obtained in the transverse direction for simplicity (i.e., $\left.t_{\text {shell }}^{z}=t_{\text {shell }}^{\perp}\right)$. Lastly, we used periodic boundary conditions in both the longitudinal and transverse directions, with respective periodicities $\Lambda^{\|}$ and $\Lambda^{\perp}$ (Table 1 ), while perfectly matched layer boundary conditions were applied in the $z$ direction. The height of the $\mathrm{Al}$ nanoparticle core, $H_{\text {core }}$, was then adjusted in order to fit the 
spectral position of the experimental transverse SPR, i.e. $\lambda_{\|}=462 \mathrm{~nm}(2.68 \mathrm{eV})$. Typically, Fig. 6(b) shows that FDTD calculations carried out by considering a transverse polarization with $H_{\text {core }}=2.6 \mathrm{~nm}$ yield well-matched experimental and simulated peak positions in the far field. The observed discrepancy between the experimental and simulated data in terms of SPR linewidth can likely be attributed to shortcomings of the optical model, which is based on the simplifying assumption that the periodic array consists of identical ellipsoidal Al nanoparticles forming a perfect network (i.e., no size/shape/position disorder). Nonetheless, the Al nanoparticles appear very flat (pancake-like with an out-of-plane aspect ratio of $H_{\text {core }} / \sqrt{D_{\text {core }}^{\|} D_{\text {core }}^{\perp}} \approx 0.22$ ), which is consistent with the low contrast of the HAADF-STEM images and with earlier studies focused on the growth of Al films on oxide surfaces. ${ }^{42,70}$ For a longitudinal excitation, the calculated absorption spectrum also correctly reproduces the plasmonic dichroism with the position of the main absorption peak at about $\lambda_{\|}=613 \mathrm{~nm}$ $(2.02 \mathrm{eV})$ being close to the experimental one. Moreover, a faint shoulder can be noticed in the NIR region beyond $800 \mathrm{~nm}(1.55 \mathrm{eV})$. As frequently stated in the literature, the plasmonic response of metallic nanostructures is highly sensitive to small variations in the optical constants of the metal. In the present case, the experimental dielectric function of $\mathrm{Al}$ was retrieved from ellipsometric measurements of a polycrystalline Al thin film which may present a high density of grain boundaries that induce a large number of scattering centers for electrons, thus leading to a reduction of their mean free path and to a plasmon damping. Accordingly, we also performed FDTD calculations using the dielectric function of Al taken from Ref. 68 [Fig. 7(a)], where both the real and imaginary parts exhibit a sharper and more intense peak localized in the region of IT. In this case, the simulated height $H_{\text {core }}$ is equal to $1.8 \mathrm{~nm}$ (out-of-plane aspect ratio of 0.15 ) and the emergence of an additional absorption band located at about $885 \mathrm{~nm}(1.40 \mathrm{eV})$ is observed in the calculated spectrum in agreement with the experimental data (Fig. 6).

Near-field calculations were also carried out using the tabulated dielectric function of Al given in Ref. 68 [Fig. 7(a)]. Fig. 8 and 9 present the spectral variations of the EMF 

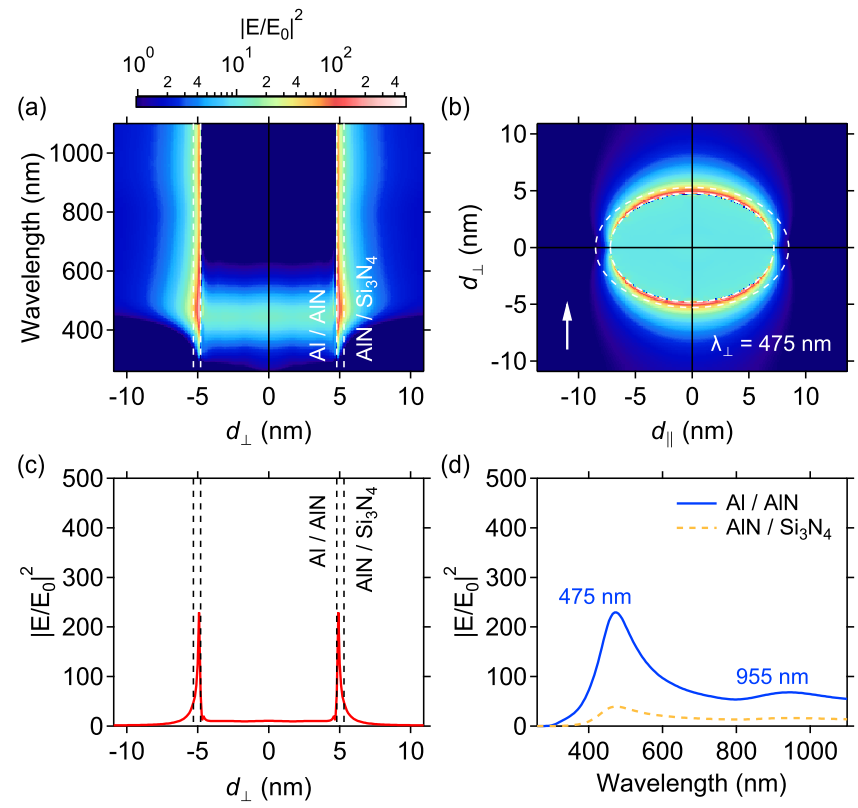

Figure 8: (a) Spectral variation of the EMF intensity calculated by FDTD for a transverse excitation along the transverse axis of $\mathrm{Si}_{3} \mathrm{~N}_{4}$-capped Al@AlN core@shell nanoparticles grown at room temperature on a rippled $\mathrm{Si}_{3} \mathrm{~N}_{4}$ thin film (the vertical dotted lines represent the location of the $\mathrm{Al} / \mathrm{AlN}$ and $\mathrm{AlN} / \mathrm{Si}_{3} \mathrm{~N}_{4}$ interfaces). (b) Map of EMF intensity calculated at a wavelength $\lambda_{\perp}=475 \mathrm{~nm}(2.61 \mathrm{eV})$ for a transverse excitation (the dotted lines indicate the dimensions and position of the nanoparticle core and shell at $z=0 \mathrm{~nm}$ ). (c) EMF intensity calculated at a wavelength $\lambda_{\perp}=475 \mathrm{~nm}(2.61 \mathrm{eV})$ for a transverse excitation along the transverse axis of the Al@AlN core@shell nanoparticles. (d) Spectral variation of the EMF intensity calculated for a transverse excitation along the transverse axis of the Al@AlN core@shell nanoparticles at the $\mathrm{Al} / \mathrm{AlN}$ and $\mathrm{AlN} / \mathrm{Si}_{3} \mathrm{~N}_{4}$ interfaces.

intensity calculated in the equatorial plane of the $\mathrm{Al}$ nanoparticles $(z=0)$ for transverse and longitudinal polarizations of the incident light, respectively. As observed in the far field, we can notice that both the SPR excitation of the nanoparticles and the plasmon-excited IT cause a significant increase of the near-field intensity at the $\mathrm{Al} / \mathrm{AlN}$ interface. Furthermore, in contrast with $\mathrm{Al} @ \mathrm{Al}_{2} \mathrm{O}_{3}$ core@shell nanoparticles deposited on a dielectric substrate, ${ }^{71}$ there is no evidence of field discontinuity at the $\mathrm{AlN} / \mathrm{Si}_{3} \mathrm{~N}_{4}$ interface because the dielectric functions of these two materials are similar in the visible-NIR region [Fig. 7(a)]. Nevertheless, the spatial location as well as the spectral positions and intensities of the near-field maxima (commonly known as 'hot spots') are clearly dependent on the polarization. The transverse mode (Fig. 8) displays a near-field enhancement at about $475 \mathrm{~nm}$ (2.61 eV), together with 

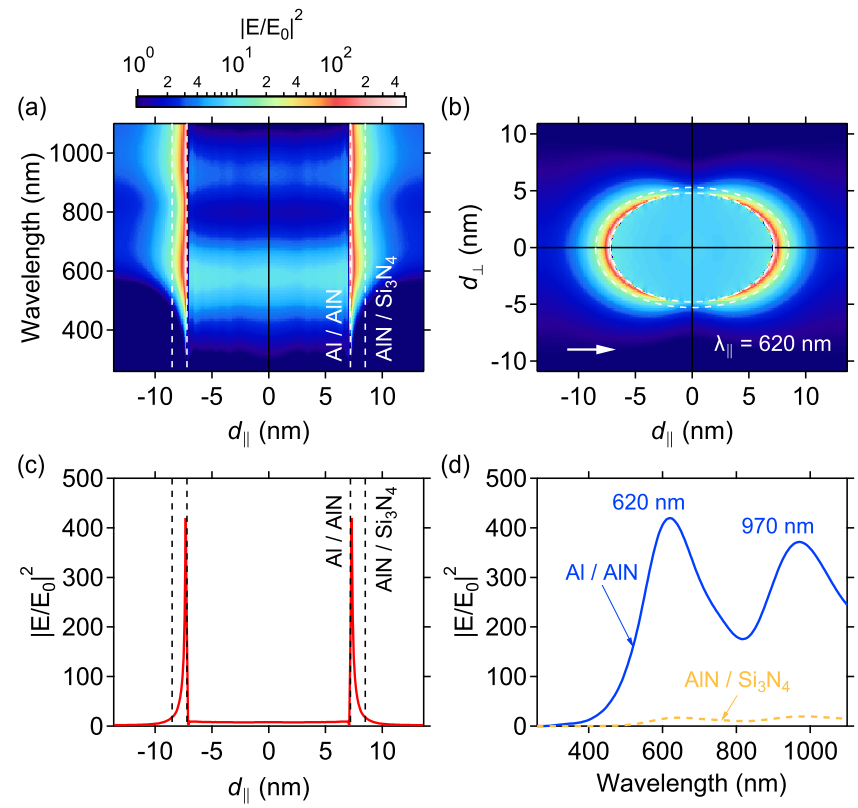

Figure 9: (a) Spectral variation of the EMF intensity calculated by FDTD for a longitudinal excitation along the longitudinal axis of $\mathrm{Si}_{3} \mathrm{~N}_{4}$-capped Al@AlN core@shell nanoparticles grown at room temperature on a rippled $\mathrm{Si}_{3} \mathrm{~N}_{4}$ thin film (the vertical dotted lines represent the location of the $\mathrm{Al} / \mathrm{AlN}$ and $\mathrm{AlN} / \mathrm{Si}_{3} \mathrm{~N}_{4}$ interfaces). (b) Map of EMF intensity calculated at a wavelength $\lambda_{\|}=620 \mathrm{~nm}(2.00 \mathrm{eV})$ for a longitudinal excitation (the dotted lines indicate the dimensions and position of the nanoparticle core and shell at $z=0 \mathrm{~nm}$ ). (c) EMF intensity calculated at a wavelength $\lambda_{\|}=620 \mathrm{~nm}(2.00 \mathrm{eV})$ for a longitudinal excitation along the longitudinal axis of the Al@AlN core@shell nanoparticles. (d) Spectral variation of the EMF intensity calculated for a longitudinal excitation along the longitudinal axis of the Al@AlN core@shell nanoparticles at the $\mathrm{Al} / \mathrm{AlN}$ and $\mathrm{AlN} / \mathrm{Si}_{3} \mathrm{~N}_{4}$ interfaces.

a second maximum of lower intensity near $955 \mathrm{~nm}(1.30 \mathrm{eV})$. It would thus appear that the overlap of the IT with the SPR is becoming more noticeable in the near field than in the far field for the transverse mode. In comparison, although the interparticle gap is not small enough to induce near-field interactions at the SPR wavelength, the ellipsoidal shape of the particles causes a spectral shift of the SPR to higher wavelengths (lower energies) for a longitudinal excitation (Fig. 9). As a consequence, the overlap between the SPR and the IT of $\mathrm{Al}$ (near $800 \mathrm{~nm}, 1.55 \mathrm{eV}$ ) induces a noticeable splitting of the EMF amplification with an intensity maximum in the red part of the spectrum, around $\lambda_{\|}=620 \mathrm{~nm}(2.00 \mathrm{eV})$, and a second near-field enhancement in the NIR region at about $\lambda_{\|}=970 \mathrm{~nm}(1.28 \mathrm{eV})$. Therefore, as described in Ref. 21 and 25, the presence of IT provides an active channel for 
SPR decay near $800 \mathrm{~nm}$. Within this bimodal profile of the EMF, which is obviously not observed in the optical response of silver or gold nanoparticles, the intensity ratio $\mid E\left(\lambda_{\|}=\right.$ $970 \mathrm{~nm}) /\left.E_{0}\right|^{2} /\left|E\left(\lambda_{\|}=620 \mathrm{~nm}\right) / E_{0}\right|^{2}$ is equal to 0.89 .

To illustrate the effect of the spectral position of the SPR and its overlap with the IT of $\mathrm{Al}$ on the far-field and near-field behavior, we performed FDTD calculations by varying the interparticle gap, $g^{\|}$. The simulated near-field and far-field spectral responses considering gaps $g^{\|}=2 D_{\text {core }}^{\|}, g^{\|}=D_{\text {core }}^{\|} / 2$, and $g^{\|}=D_{\text {core }}^{\|} / 4$, respectively, are presented in the Supporting Information (Fig. S3). For comparison, in Fig. 6(b) and 9, it should be recalled that we considered an interparticle gap of $g^{\|} \approx 0.9 D_{\text {core }}^{\|}$as determined experimentally by EF-TEM analysis (Table 1). It is well known that the reduction of the gap induces a spectral red-shift of the SPR together with a huge increase of the nearfield intensity at the SPR wavelength. Hence the bimodal shape of the EMF intensity is modified as the interparticle gap is reduced. Specifically, the intensity ratio gradually increases from $\left|E\left(\lambda_{\|}=970 \mathrm{~nm}\right) / E_{0}\right|^{2} /\left|E\left(\lambda_{\|}=610 \mathrm{~nm}\right) / E_{0}\right|^{2}=0.75$ for $g^{\|}=2 D_{\text {core }}^{\|}$to $\left|E\left(\lambda_{\|}=980 \mathrm{~nm}\right) / E_{0}\right|^{2} /\left|E\left(\lambda_{\|}=650 \mathrm{~nm}\right) / E_{0}\right|^{2}=1.42$ for $g^{\|}=D_{\text {core }}^{\|} / 4$. It is also worth noting that, while the spectral position of the near-field enhancement corresponding to the absorption peak located in the visible red-shifts from $\lambda_{\|} \approx 610 \mathrm{~nm}(2.03 \mathrm{eV})$ to $\lambda_{\|} \approx 650 \mathrm{~nm}$ $(1.91 \mathrm{eV})$ when $g^{\|}$is decreased from $2 D_{\text {core }}^{\|}$to $D_{\text {core }}^{\|} / 4$, the spectral position of the near-field NIR enhancement remains almost unchanged at about $970-980 \mathrm{~nm}(1.28-1.27 \mathrm{eV})$. Therefore, our FDTD calculations reveal that the coupling between the longitudinal SPR and the IT of Al could be tailored, which in turn would offer potential for near-field enhancement in the visible or NIR region.

\section{Thermal treatments}

In order to check the thermal stability of Al@AlN core@shell nanoparticles embedded in $\mathrm{Si}_{3} \mathrm{~N}_{4}$, cumulative annealing treatments were performed at 200,300 , and $400^{\circ} \mathrm{C}$ for $1 \mathrm{~h}$ under vacuum $\left(\sim 2 \times 10^{-7}\right.$ mbar $)$. Obviously, EF-TEM images acquired at $15.5 \pm 0.5 \mathrm{eV}$ 
[Fig. S4(a) and S4(c), Supporting Information] and at 17.5 $\pm 0.5 \mathrm{eV}$ [Fig. S4(b) and S4(d), Supporting Information] energy losses show that thermal annealing has a negligible impact on the structure and in-plane morphology of the Al@AlN core@shell nanoparticles (see also Table 1), which tends to confirm that the existence of an AlN shell is beneficial for the stability of the $\mathrm{Al} / \mathrm{Si}_{3} \mathrm{~N}_{4}$ interface at moderate temperatures. ${ }^{65,72}$ Fig. 10 shows the evolution of the absorbance spectra collected with longitudinal and transverse polarizations of the incident light, together with the evolution of the transverse SPR position $\lambda_{\perp}$ after cumulative treatments at increasing temperatures. In view of the above findings, the spectral blue-shift of the transverse SPR from $\lambda_{\perp} \approx 462 \mathrm{~nm}(2.68 \mathrm{eV})$ to $406 \mathrm{~nm}(3.05 \mathrm{eV})$ might be attributed to a slight increase of the out-of-plane aspect ratio of the nanoparticles. Using the tabulated dielectric function taken from Ref. 68 [Fig. 7(a)], this would be consistent with an increase of the nanoparticle height from $H_{\text {core }}=1.8 \mathrm{~nm}$ (as-grown) to 2.0 and $2.3 \mathrm{~nm}$ after annealing at 300 and $400^{\circ} \mathrm{C}$, respectively. However, besides the morphology of the nanoparticles and their average dimensions, the dielectric properties of the metal and nanoscale surface roughness may play an important role, ${ }^{55,73,74}$ which could affect the accuracy of the modeling and the interpretation of the results. Thus, the blue-shift and narrowing of the transverse and longitudinal absorption bands could also result from thermally-induced changes in the metal crystallinity, number of grain boundaries inside the metal core, and surface roughness of the Al nanoparticles.

\section{Conclusions}

In summary, we conducted an experimental and numerical study on the optical properties of ultrafine $\mathrm{Al}$ nanoparticles obtained by physical vapor deposition on rippled silicon nitride surfaces. Our results show that the formation of periodic chains of nanoparticles that replicate the in-plane organization of the underlying ripple pattern can be successfully achieved through glancing-angle deposition. EF-TEM and EF-SAED analyses highlight an Al@AlN 


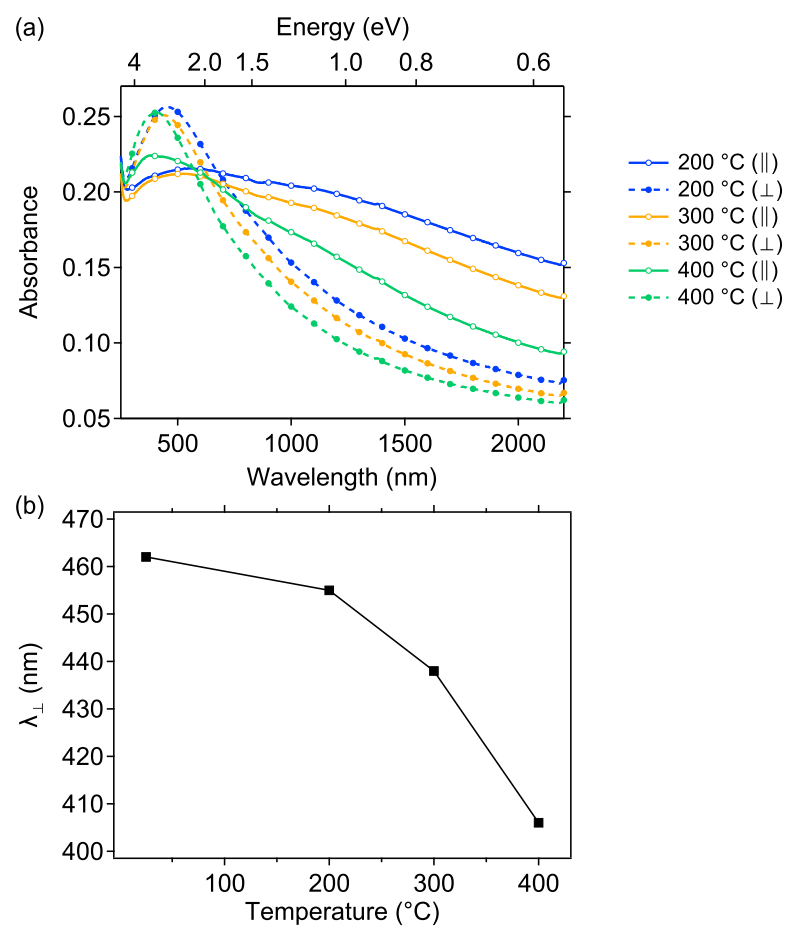

Figure 10: (a) Experimental absorption spectra with longitudinal and transverse polarizations of the incident light after cumulative annealing treatments at 200,300 , and $400{ }^{\circ} \mathrm{C}$ for $1 \mathrm{~h}$ under vacuum $\left(\sim 2 \times 10^{-7} \mathrm{mbar}\right)$ of $\mathrm{Si}_{3} \mathrm{~N}_{4}$-capped $\mathrm{Al}$ nanoparticles grown at room temperature on a rippled $\mathrm{Si}_{3} \mathrm{~N}_{4}$ thin film $\left(t_{\mathrm{Al}}=2.9 \mathrm{~nm}\right)$. (b) Thermal evolution of the transverse SPR position, $\lambda_{\perp}$.

core@shell structure that originates from the growth of the silicon nitride capping-layer, which in turn provides efficient protection for the nanoparticles against ageing and thermal effects at moderate temperature. From our FDTD calculations, the far-field dichroic behavior of the nanoparticle assembly can be understood as the optical response of very flat ellipsoids whose longitudinal SPR overlaps with the IT of Al. For a longitudinal polarization of the incident light, this interaction is reflected in the decay of the SPR via interband excitations, which induces a decrease in the absorption spectrum as well as in the near-field enhancement around $800 \mathrm{~nm}(1.55 \mathrm{eV})$. This results in an apparent splitting of the EMF amplification and in a near-field enhancement both at visible and NIR wavelengths around $580-620 \mathrm{~nm}$ $(2.14-2.00 \mathrm{eV})$ and $910-970 \mathrm{~nm}(1.36-1.28 \mathrm{eV})$, respectively. In contrast, for a transverse excitation, the coupling between the SPR - located at about $460-475 \mathrm{~nm}(2.70-2.61 \mathrm{eV})-$ and the IT is strongly reduced, which leads to the emergence of a single absorption band in 
the far field and to the weakening of the effect of SPR decay on the near-field enhancement in the NIR region. The polarization-dependent plasmonic response of these systems suggests a potential for tunable near-field enhancement in the blue (transverse polarization), in the red or the NIR (longitudinal polarization) regions, which may open up promising opportunities for plasmon-enhanced photovoltaics or thermoplasmonic and sensing applications.

\section{Acknowledgement}

We acknowledge the assistance of P. Guérin during the sample preparation. We also thank Prof. G. Abadias and Dr. L. Simonot for performing AFM characterizations. This work was partially funded by the "Région Nouvelle-Aquitaine" and the European Regional Development Fund (ERDF 2014-2020) within the IMATOP project No. P-2016-BAFE-209.

\section{Supporting Information Available}

- Fig. S1: EF-TEM analysis

- Fig. S2: Stability over time

- Fig. S3: Influence of the interparticle gap

- Fig. S4: Thermal treatments

This material is available free of charge via the Internet at http://pubs.acs.org/.

\section{References}

(1) Kreibig, U.; Vollmer, M. Optical Properties of Metal Clusters; Springer: Berlin, 1999.

(2) Kelly, K. L.; Coronado, E.; Zhao, L. L.; Schatz, G. C. The optical properties of metal nanoparticles: The influence of size, shape, and dielectric environment. J. Phys. Chem. B 2003, 107, 668-677. 
(3) Maier, S. A. Plasmonics: Fundamentals and Applications; Springer US, 2007.

(4) Atwater, H. A.; Polman, A. Plasmonics for improved photovoltaic devices. Nat. Mater. 2010, 9, 205-213.

(5) Engheta, N. Circuits with light at nanoscales: optical nanocircuits inspired by metamaterials. Science 2007, 317, 1698-1702.

(6) Wang, X.; Morea, R.; Gonzalo, J.; Palpant, B. Coupling localized plasmonic and photonic modes tailors and boosts ultrafast light modulation by gold nanoparticles. Nano Lett. 2015, 15, 2633-2639.

(7) Löfås, S.; Malmqvist, M.; Rönnberg, I.; Stenberg, E.; Liedberg, B.; Lundström, I. Bioanalysis with surface plasmon resonance. Sens. Actuators B-Chem. 1991, 5, 79-84.

(8) Kaminska, I.; Maurer, T.; Nicolas, R.; Renault, M.; Lerond, T.; Salas-Montiel, R.; Herro, Z.; Kazan, M.; Niedziolka-Jönsson, J.; Plain, J. et al. Near-field and far-field sensitivities of LSPR sensors. J. Phys. Chem. C 2015, 119, 9470-9476.

(9) Baffou, G.; Quidant, R. Thermo-plasmonics: using metallic nanostructures as nanosources of heat. Laser Photon. Rev. 2013, 7, 171-187.

(10) Anger, P.; Bharadwaj, P.; Novotny, L. Enhancement and quenching of single-molecule fluorescence. Phys. Rev. Lett. 2006, 96, 113002.

(11) Fort, E.; Grésillon, S. Surface enhanced fluorescence. J. Phys. D-Appl. Phys. 2008, 41, 013001.

(12) Khlebtsov, N. G.; Dykman, L. A. Optical properties and biomedical applications of plasmonic nanoparticles. J. Quant. Spectrosc. Radiat. Transf. 2010, 111, 1-35.

(13) Fan, M.; Andrade, G. F.; Brolo, A. G. A review on the fabrication of substrates for surface enhanced Raman spectroscopy and their applications in analytical chemistry. Anal. Chim. Acta 2011, 693, 7-25. 
(14) Cialla, D.; März, A.; Böhme, R.; Theil, F.; Weber, K.; Schmitt, M.; Popp, J. Surfaceenhanced Raman spectroscopy (SERS): progress and trends. Anal. Bioanal. Chem. 2012, 403, 27-54.

(15) Toudert, J.; Simonot, L.; Camelio, S.; Babonneau, D. Advanced optical effective medium modeling for a single layer of polydisperse ellipsoidal nanoparticles embedded in a homogeneous dielectric medium: Surface plasmon resonances. Phys. Rev. B 2012, 86, 045415 .

(16) West, P.; Ishii, S.; Naik, G.; Emani, N.; Shalaev, V.; Boltasseva, A. Searching for better plasmonic materials. Laser Photon. Rev. 2010, 4, 795-808.

(17) Lalisse, A.; Tessier, G.; Plain, J.; Baffou, G. Quantifying the efficiency of plasmonic materials for near-field enhancement and photothermal conversion. J. Phys. Chem. C 2015, 119, 25518-25528.

(18) Gérard, D.; Gray, S. K. Aluminium plasmonics. J. Phys. D-Appl. Phys. 2015, 48, 184001.

(19) Knight, M. W.; King, N. S.; Liu, L.; Everitt, H. O.; Nordlander, P.; Halas, N. J. Aluminum for plasmonics. ACS Nano 2014, 8, 834-840.

(20) Knight, M. W.; Liu, L.; Wang, Y.; Brown, L.; Mukherjee, S.; King, N. S.; Everitt, H. O.; Nordlander, P.; Halas, N. J. Aluminum plasmonic nanoantennas. Nano Lett. 2012, 12, 6000-6004.

(21) Lecarme, O.; Sun, Q.; Ueno, K.; Misawa, H. Robust and versatile light absorption at near-infrared wavelengths by plasmonic aluminum nanorods. ACS Photonics 2014, 1, $538-546$.

(22) Langhammer, C.; Schwind, M.; Kasemo, B.; Zorić, I. Localized surface plasmon resonances in aluminum nanodisks. Nano Lett. 2008, 8, 1461-1471. 
(23) Chan, G. H.; Zhao, J.; Schatz, G. C.; Van Duyne, R. P. Localized surface plasmon resonance spectroscopy of triangular aluminum nanoparticles. J. Phys. Chem. C 2008, 112, 13958-13963.

(24) Ekinci, Y.; Solak, H. H.; Löffler, J. F. Plasmon resonances of aluminum nanoparticles and nanorods. J. Appl. Phys. 2008, 104, 083107.

(25) Zorić, I.; Zäch, M.; Kasemo, B.; Langhammer, C. Gold, platinum, and aluminum nanodisk plasmons: Material independence, subradiance, and damping mechanisms. ACS Nano 2011, 5, 2535-2546.

(26) Martin, J.; Kociak, M.; Mahfoud, Z.; Proust, J.; Gérard, D.; Plain, J. High-resolution imaging and spectroscopy of multipolar plasmonic resonances in aluminum nanoantennas. Nano Lett. 2014, 14, 5517-5523.

(27) Villesen, T. F.; Uhrenfeldt, C.; Johansen, B.; Lundsgaard Hansen, J.; Ulriksen, H. U.; Nylandsted Larsen, A. Aluminum nanoparticles for plasmon-improved coupling of light into silicon. Nanotechnology 2012, 23, 085202.

(28) Gillibert, R.; Colas, F.; Yasukuni, R.; Picardi, G.; Lamy de la Chapelle, M. Plasmonic properties of aluminum nanocylinders in the visible range. J. Phys. Chem. C 2017, 121, 2402-2409.

(29) Taguchi, A.; Saito, Y.; Watanabe, K.; Yijian, S.; Kawata, S. Tailoring plasmon resonances in the deep-ultraviolet by size-tunable fabrication of aluminum nanostructures. Appl. Phys. Lett. 2012, 101, 081110.

(30) Tan, S. J.; Zhang, L.; Zhu, D.; Goh, X. M.; Wang, Y. M.; Kumar, K.; Qiu, C.-W.; Yang, J. K. W. Plasmonic color palettes for photorealistic printing with aluminum nanostructures. Nano Lett. 2014, 14, 4023-4029. 
(31) Goh, X. M.; Zheng, Y.; Tan, S. J.; Zhang, L.; Kumar, K.; Qiu, C.-W.; Yang, J. K. W. Three-dimensional plasmonic stereoscopic prints in full colour. Nat. Commun. 2014, 5, 5361.

(32) Hu, J.; Chen, L.; Lian, Z.; Cao, M.; Li, H.; Sun, W.; Tong, N.; Zeng, H. Deepultraviolet-blue-light surface plasmon resonance of $\mathrm{Al}$ and $\mathrm{Al}_{\text {core }} / \mathrm{Al}_{2} \mathrm{O}_{3 \text { shell }}$ in spherical and cylindrical nanostructures. J. Phys. Chem. C 2012, 116, 15584-15590.

(33) Martin, J.; Proust, J.; Gérard, D.; Plain, J. Localized surface plasmon resonances in the ultraviolet from large scale nanostructured aluminum films. Opt. Mater. Express 2013, 3, 954-959.

(34) Maidecchi, G.; Gonella, G.; Proietti Zaccaria, R.; Moroni, R.; Anghinolfi, L.; Giglia, A.; Nannarone, S.; Mattera, L.; Dai, H.-L.; Canepa, M. et al. Deep ultraviolet plasmon resonance in aluminum nanoparticle arrays. ACS Nano 2013, 7, 5834-5841.

(35) Bisio, F.; Proietti Zaccaria, R.; Moroni, R.; Maidecchi, G.; Alabastri, A.; Gonella, G.; Giglia, A.; Andolfi, L.; Nannarone, S.; Mattera, L. et al. Pushing the high-energy limit of plasmonics. ACS Nano 2014, 8, 9239-9247.

(36) Villesen, T. F.; Uhrenfeldt, C.; Johansen, B.; Nylandsted Larsen, A. Self-assembled Al nanoparticles on Si and fused silica, and their application for Si solar cells. Nanotechnology 2013, 24, 275606.

(37) Kochergin, V.; Neely, L.; Jao, C.-Y.; Robinson, H. D. Aluminum plasmonic nanostructures for improved absorption in organic photovoltaic devices. Appl. Phys. Lett. 2011, 98,133305 .

(38) Zhang, Y.; Ouyang, Z.; Stokes, N.; Jia, B.; Shi, Z.; Gu, M. Low cost and high performance Al nanoparticles for broadband light trapping in Si wafer solar cells. Appl. Phys. Lett. 2012, 100, 151101. 
(39) Abdulrahman, R. B.; Cansizoglu, H.; Cansizoglu, M. F.; Herzog, J. B.; Karabacak, T. Enhanced light trapping and plasmonic properties of aluminum nanorods fabricated by glancing angle deposition. J. Vac. Sci. Technol. A 2015, 33, 041501.

(40) Bisio, F.; Gonella, G.; Maidecchi, G.; Buzio, R.; Gerbi, A.; Moroni, R.; Giglia, A.; Canepa, M. Broadband plasmonic response of self-organized aluminium nanowire arrays. J. Phys. D-Appl. Phys. 2015, 48, 184003.

(41) Wiecha, P. R.; Mennemanteuil, M.-M.; Khlopin, D.; Martin, J.; Arbouet, A.; Gérard, D.; Bouhelier, A.; Plain, J.; Cuche, A. Local field enhancement and thermoplasmonics in multimodal aluminum structures. Phys. Rev. B 2017, 96, 035440.

(42) Anno, E.; Tanimoto, M. Size-dependent change in parallel band absorption of Al particles. Phys. Rev. B 2001, 64, 165407.

(43) Ray, K.; Chowdhury, M. H.; Lakowicz, J. R. Aluminum nanostructured films as substrates for enhanced fluorescence in the ultraviolet-blue spectral region. Anal. Chem. 2007, $79,6480-6487$.

(44) Zhao, C.; Zhu, Y.; Su, Y.; Guan, Z.; Chen, A.; Ji, X.; Gui, X.; Xiang, R.; Tang, Z. Tailoring plasmon resonances in aluminium nanoparticle arrays fabricated using anodic aluminium oxide. Adv. Opt. Mater. 2015, 3, 248-256.

(45) Wei, Z.; Mao, P.; Cao, L.; Song, F. Probing plasmon resonances of individual aluminum nanoparticles. Mod. Phys. Lett. B 2018, 32, 1850032.

(46) Stratakis, E.; Barberoglou, M.; Fotakis, C.; Viau, G.; Garcia, C.; Shafeev, G. A. Generation of $\mathrm{Al}$ nanoparticles via ablation of bulk $\mathrm{Al}$ in liquids with short laser pulses. Opt. Express 2009, 17, 12650-12659.

(47) Meziani, M. J.; Bunker, C. E.; Lu, F.; Li, H.; Wang, W.; Guliants, E. A.; Quinn, R. A.; 
Sun, Y.-P. Formation and properties of stabilized aluminum nanoparticles. ACS Appl. Mater. Interfaces 2009, 1, 703-709.

(48) Martin, J.; Plain, J. Fabrication of aluminium nanostructures for plasmonics. J. Phys. D-Appl. Phys. 2015, 48, 184002.

(49) Nakamura, R.; Tokozakura, D.; Nakajima, H.; Lee, J.-G.; Mori, H. Hollow oxide formation by oxidation of $\mathrm{Al}$ and $\mathrm{Cu}$ nanoparticles. J. Appl. Phys. 2007, 101, 074303.

(50) Maidecchi, G.; Duc, C. V.; Buzio, R.; Gerbi, A.; Gemme, G.; Canepa, M.; Bisio, F. Electronic structure of core-shell metal/oxide aluminum nanoparticles. J. Phys. Chem. C 2015, 119, 26719-26725.

(51) Oates, T. W. H.; Keller, A.; Noda, S.; Facsko, S. Self-organized metallic nanoparticle and nanowire arrays from ion-sputtered silicon templates. Appl. Phys. Lett. 2008, 93, 063106.

(52) Camelio, S.; Babonneau, D.; Lantiat, D.; Simonot, L.; Pailloux, F. Anisotropic optical properties of silver nanoparticle arrays on rippled dielectric surfaces produced by lowenergy ion erosion. Phys. Rev. B 2009, 80, 155434.

(53) Babonneau, D.; Camelio, S.; Simonot, L.; Pailloux, F.; Guérin, P.; Lamongie, B.; Lyon, O. Tunable plasmonic dichroism of Au nanoparticles self-aligned on rippled $\mathrm{Al}_{2} \mathrm{O}_{3}$ thin films. EPL 2011, 93, 26005.

(54) Camelio, S.; Vandenhecke, E.; Rousselet, S.; Babonneau, D. Optimization of growth and ordering of Ag nanoparticle arrays on ripple patterned alumina surfaces for strong plasmonic coupling. Nanotechnology 2014, 25, 035706.

(55) Yazidi, S.; Fafin, A.; Rousselet, S.; Pailloux, F.; Camelio, S.; Babonneau, D. Structure and far-field optical properties of self-organized bimetallic $\mathrm{Au}_{x-\mathrm{-}} \mathrm{Ag}_{1-x}$ nanoparticles 
embedded in alumina thin films. Phys. Status Solidi C-Current Topics in Solid State Phys. 2015, 12, 1344-1348.

(56) Garel, M.; Babonneau, D.; Boulle, A.; Pailloux, F.; Coati, A.; Garreau, Y.; Ramos, A. Y.; Tolentino, H. C. N. Self-organized ultrathin FePt nanowires produced by glancing-angle ion-beam codeposition on rippled alumina surfaces. Nanoscale $\mathbf{2 0 1 5}$, 7, $1437-1445$.

(57) Babonneau, D.; Camelio, S.; Vandenhecke, E.; Rousselet, S.; Garel, M.; Pailloux, F.; Boesecke, P. Quantitative analysis of nanoripple and nanoparticle patterns by grazing incidence small-angle x-ray scattering 3D mapping. Phys. Rev. B 2012, 85, 235415.

(58) Alix, K.; David, M.-L.; Lucas, G.; Alexander, D. T.; Pailloux, F.; Hébert, C.; Pizzagalli, L. Gentle quantitative measurement of helium density in nanobubbles in silicon by spectrum imaging. Micron 2015, 77, 57-65.

(59) Egerton, R. F. Electron Energy-Loss Spectroscopy in the Electron Microscope; Springer: New York, NY, 2011.

(60) Lumerical Inc. (Vancouver, Canada). http://www.lumerical.com/tcad-products/ fdtd/.

(61) Camelio, S.; Babonneau, D.; Lantiat, D.; Simonot, L. Self-organized growth and optical properties of silver nanoparticle chains and stripes. EPL 2007, 79, 47002.

(62) Joint Committee on Powder Diffraction Standards. JCPDS-ICDD Powder Diffraction Database, cards No. 4-787 (fcc-Al) and 25-1133 (w-AlN).

(63) Palisaitis, J.; Hsiao, C.-L.; Junaid, M.; Birch, J.; Hultman, L.; Persson, P. O. A. Effect of strain on low-loss electron energy loss spectra of group-III nitrides. Phys. Rev. B 2011, 84, 245301.

(64) EELS Data Base. https://eelsdb.eu/spectra/silicon-nitride-alpha-2/. 
(65) Brener, R.; Edelman, F.; Gutmanas, E. Y. Formation of an interfacial AlN layer in an $\mathrm{Al} / \mathrm{Si}_{3} \mathrm{~N}_{4}$ thin-film system. Appl. Phys. Lett. 1989, 54, 901-903.

(66) Losquin, A.; Camelio, S.; Rossouw, D.; Besbes, M.; Pailloux, F.; Babonneau, D.; Botton, G. A.; Greffet, J.-J.; Stéphan, O.; Kociak, M. Experimental evidence of nanometerscale confinement of plasmonic eigenmodes responsible for hot spots in random metallic films. Phys. Rev. B 2013, 88, 115427.

(67) Pakizeh, T. Optical absorption of plasmonic nanoparticles in presence of a local interband transition. J. Phys. Chem. C 2011, 115, 21826-21831.

(68) Palik, E. D. Handbook of Optical Constants of Solids; Academic Press: Burlington, 1997.

(69) Özgür, U.; Webb-Wood, G.; Everitt, H. O.; Yun, F.; Morkoç, H. Systematic measurement of $\mathrm{Al}_{x} \mathrm{Ga}_{1-x} \mathrm{~N}$ refractive indices. Appl. Phys. Lett. 2001, 79, 4103-4105.

(70) Lazzari, R.; Simonsen, I.; Bedeaux, D.; Vlieger, J.; Jupille, J. Polarizability of truncated spheroidal particles supported by a substrate: Model and applications. Eur. Phys. J. B 2001, 24, 267-284.

(71) Gutierrez, Y.; Ortiz, D.; Sanz, J. M.; Saiz, J. M.; Gonzalez, F.; Everitt, H. O.; Moreno, F. How an oxide shell affects the ultraviolet plasmonic behavior of $\mathrm{Ga}, \mathrm{Mg}$, and Al nanostructures. Opt. Express 2016, 24, 20621-20631.

(72) Avila, J.; Sacedón, J. L. Reactivity at the $\mathrm{Al} / \mathrm{Si}_{3} \mathrm{~N}_{4}$ interfaces. Appl. Phys. Lett. 1995, $66,757-759$.

(73) Tinguely, J.-C.; Sow, I.; Leiner, C.; Grand, J.; Hohenau, A.; Felidj, N.; Aubard, J.; Krenn, J. R. Gold nanoparticles for plasmonic biosensing: The role of metal crystallinity and nanoscale roughness. BioNanoScience 2011, 1, 128-135. 
(74) Zhang, F.; Proust, J.; GÃl'rard, D.; Plain, J.; Martin, J. Reduction of plasmon damping in aluminum nanoparticles with rapid thermal annealing. J. Phys. Chem. C 2017, 121, $7429-7434$. 
Graphical TOC Entry

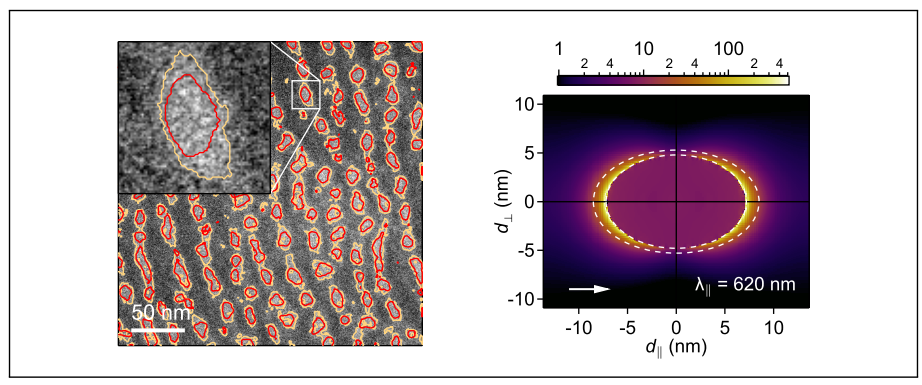

